\title{
Contribuição das boas práticas do mercado para a eficiência na gestão de risco corporativo
}

\author{
Contribution of good practices in the market to the \\ efficiency in the enterprise risk management
}

Hong Yuh Ching

Doutor em Engenharia Mecânica pela Universidade Estadual de Campinas (UNICAMP), coordenador do Curso de Administração do Centro Universitário da FEI, São Bernardo do Campo, SP - Brasil, e-mail: hongching@fei.edu.br

\section{Resumo}

A gestão de risco corporativo, ou Enterprise Risk Management - ERM - possibilita às empresas se beneficiarem de um enfoque integrado que desvie seu foco de uma situação defensiva de mitigação de risco para estratégia e de agregação de valor aos acionistas. Os objetivos da pesquisa são: fazer uma comparação das práticas de gestão de risco utilizadas no estudo de caso com as boas práticas do mercado, tendo como referencial as boas práticas extraídas de três estudos; pesquisar diferentes modelos ou estruturas de gestão de risco corporativo e se o seu emprego contribui para a eficiência na gestão desses riscos. 0 método de pesquisa é qualitativo do tipo exploratório com estudo de um único caso. A coleta de dados foi feita por meio de material obtido de documentos internos fornecidos pela empresa, entrevistas com dois gestores e visita in loco. Os resultados mostram que a empresa atende uma grande parte das boas práticas de mercado e, portanto, seu nível de eficiência na gestão dos riscos já se encontra em um patamar bastante satisfatório. Duas foram as conclusões do trabalho: a) o nível de eficiência na gestão de riscos da Comgás tem relação com a utilização das boas práticas de mercado. Quanto mais práticas estiverem sendo aplicadas na empresa, maior será seu nível de eficiência; b) o emprego de uma estrutura formal ou modelo de ERM contribui significativamente para essa eficiência.

Palavras-chave: Boas práticas. Gestão de risco corporativo. ERM.

\section{Abstract}

ERM enables companies to benefit from an integrated approach that shifts its focus from primarily defensive to strategic and added value to the shareholders. The objectives of the research are twofold: to compare the risk management practices used in the case study with the good practices in place in the market, having as reference good practices extracted from three studies; to research different frameworks of corporate risk management and whether its use contributes to the efficiency of risk management. The methodology is exploratory with one single case study. Data were obtained from the internal documents, interviews with two executives and visit on site. Results show that company is in conformance with a great deal of good practices in the market and, however, its efficiency level is already in a very satisfactory level. Conclusions are as follows: a) the risk management efficiency level at Comgás is 
related to the utilization of market good practices. More practices being utilized better will be its efficiency level; b) the use of a formal ERM framework contributes highly to this efficiency.

Keywords: Good practices. Enterprise risk management. ERM.

\section{Introdução}

Uma pesquisa conduzida por Généreux, Lamarre e Leutier (2003) mostra que 36\% dos diretores participantes não entendem totalmente os riscos que seus negócios enfrentam; $24 \%$ deles disseram que os processos da diretoria para controlar a gestão de risco eram ineficazes e 19\% disseram que suas diretorias não tinham sequer processos para lidar com risco. Para várias empresas, gestão de risco tem como único foco proteger a empresa de possíveis perdas, seja, para evitar ou para mitigar o risco. Visto desta forma, o risco é tratado como uma ameaça. Para autores como Buehler e Pritsch (2003), risco é um fato da vida empresarial. Assumir ou gerenciar risco é parte do que as empresas devem fazer para criar lucro e valor aos acionistas. Para eles, as empresas devem fazer escolhas entre os tipos de risco e montante de risco que estão dispostas a tomar.

Para Vila (2003), o termo "Gestão de Risco" deve ser entendido como uma abordagem sistemática no estabelecimento do curso de ação frente às incertezas, pela identificação, avaliação, compreensão, ação e comunicação dos itens de risco. Definição similar é explicitada na norma ABNT/ISO 31000 (2009), sendo que nela entende-se a Gestão de Risco como a aplicação sistemática de políticas, procedimentos e práticas de gestão para as atividades de comunicação, consulta, estabelecimento do contexto, e na identificação, análise, avaliação, tratamento, monitoramento e análise crítica dos riscos. A eficácia do trabalho de administração do risco dependerá de algumas ações, tais como: abrangências e rigor na análise do risco, análise dos efeitos do risco sobre o programa, adoção de medidas para sua eliminação ou mitigação e agilidade e tempestividade das ações acima (VILA, 2003).

Para várias entidades, como The Risk Management Association (RMA), The Committee of Sponsoring Organizations of The Treadway Commission (COSO), Risk and Insurance Management Society (RIMS) e Casualty \&Actuarial Society (CAS), o conceito de gestão de risco deve ser ampliado para uma visão corporativa, deixando de ser analisados tipos de risco e/ ou áreas da empresa individualmente, para ser analisada a empresa em seu todo, a fim de se obter um gerenciamento eficiente. Daí a expressão Enterprise Risk Management - ERM, ou gestão de risco corporativo como o novo enfoque.

Afinal, o que significa ERM? Não há um claro entendimento do que significa ERM. As organizações estão com problema em definir seus programas, onde e como começar, e quem deve ser envolvido. Uma amostra de três organizações, CAS, COSO e IIA Institute for Internal Auditors, revela que não existe uniformidade na sua definição (DELOITTE, 2008). COSO define como um processo implementado pelos diretores, gerentes e colaboradores de uma empresa, aplicado no estabelecimento de uma estratégia e por toda a empresa, desenhado para identificar potenciais eventos que possam afetar a empresa e gerenciar risco nos limites do seu apetite de risco e assim assegurar de forma razoável a realização dos resultados. Outra definição é fornecida pela RIMS, que entende ERM como sendo a cultura, processos e ferramentas para identificar oportunidades, estratégicas e reduzir incerteza. ERM é uma visão abrangente do risco, tanto da perspectiva operacional como estratégica, e é um processo que suporta a redução de incerteza e promove a obtenção das oportunidades. Por fim, CAS define como sendo a disciplina pela qual uma organização, em qualquer indústria, avalia, controla, financia e monitora riscos de todas as fontes para o propósito de aumentar o valor de curto e longo prazo da organização aos seus acionistas. Um estudo de várias definições revela que todas têm em comum três características críticas (IBM, 2005):

a) integrado: ERM deve cobrir todas as linhas de negócio;

b) abrangente: ERM deve incluir todos os tipos de risco;

c) estratégico: ERM deve estar alinhado com a estratégia geral do negócio.

Um estudo da Corporate Executive Board (2007) aponta vários fatores que pressionam as empresas 
a adotarem melhores processos de gestão de risco, a saber:

a) adequação das empresas norte-americanas e empresas estrangeiras, com ações na bolsa de valores nos EUA, às normas americanas como a Lei Sarbanes-Oxley, criada em 2002 com a finalidade de proteger investidores;

b) a estrutura da gestão de risco com ênfase em toda a empresa que o COSO propõe e esteja integrada na estratégia corporativa;

c) a Comissão de Valores Mobiliários norte-americana (SEC) urge as empresas listadas a usarem as informações advindas do ERM para melhorarem a transparência nas discussões e análises gerenciais;

d) agências de rating começam a incorporar a avaliação de ERM nos seus relatórios. Isso também é verificado na pesquisa da Deloitte (2008), em que esse item é o fator mais importante;

e) $48 \%$ das empresas já estabeleceram total ou parcialmente o ERM, enquanto 38\% planejam sua implementação (fonte: Treasury Leadership Roundtable Research de janeiro 2007, CFO Executive Board Research). Estudo de Beasley, Clune e Fermanson (2005) mostra resultados parecidos, em que 37\% das empresas têm planos de ERM parcialmente implementados e 11\% têm sistema pleno de ERM em ação.

Além de coincidir em alguns fatores acima mencionados, CAS (2003) lista outros fatores adicionais:

a) reconhecimento de que as empresas enfrentam um número crescente de riscos e que se interagem. Em adição aos riscos conhecidos (incêndio e garantia de produto), empresas lidam com outros riscos menos tradicionais (necessidade de hedging nos negócios), novos riscos como a falha de mecanismos de controle (caso da Societe Generalli) e atividades terroristas e falta de entendimento da dinâmica dos negócios (caso recente da crise imobiliária nos Estados Unidos);

b) inclusão dos riscos da empresa na teoria do portfólio, de modo que o risco do portfólio considere os riscos individuais e suas interações. 0 risco total do portfólio não é a soma dos riscos individuais, pois alguns riscos podem ser hedge natural contra outros, contanto que sejam correlacionados negativamente;

c) tendência crescente nas empresas de quantificarem os riscos para terem uma melhor perspectiva qualitativa dos riscos, à semelhança do que ocorre no mercado financeiro com o modelo de Value at Risk. As empresas podem se beneficiar dos cenários "whatif", estimando a magnitude dos riscos ou o grau de dependência entre os riscos individuais, para tomar melhores decisões;

d) riscos estão sendo considerados como fonte de oportunidades de criação de valor e não algo a ser minimizado ou evitado. Risco não é completamente evitável, mas saber avaliar risco e seu retorno é uma forma de se obter vantagem competitiva. As empresas estão passando a adotar ERM como uma ferramenta de vantagem estratégica.

A gestão de risco corporativo deve ser usada proativamente para balancear risco, oportunidade e valor. Ela lida com esses elementos que afetam a criação de valor da empresa e como o sucesso dessa gestão está relacionado com a aderência da empresa na utilização das melhores práticas. 0 objetivo da pesquisa é fazer uma comparação das práticas de gestão de risco utilizadas no estudo de caso (no caso, a Comgás) com as melhores práticas do mercado, tendo como referencial teórico as boas práticas extraídas de uma pesquisa da The Economist Intelligence Unit (EIU) (2007, outra da Deloitte (2008) e do estudo da Aon (2010). 0 objetivo secundário é pesquisar diferentes modelos ou estruturas de gestão de risco corporativo e se o seu emprego contribui para a eficiência na gestão desses riscos.

\section{Referencial teórico}

Foram encontrados poucos trabalhos e artigos de cunho acadêmico ligados à área de gestão de risco corporativo, porém mais concentrados nos seus aspectos gerais. Exemplos são os artigos de Liebenberg e Hoyt e Kleffner, Lee e McGannon. 0 artigo de Liebenberg e Hoyt (2003) confirma que pouca pesquisa empírica tem sido conduzida nessa área. Seu estudo fornece uma tentativa de identificar os determinantes para adoção do ERM, com ênfase nas empresas que haviam apontado o Chief Risk Officer - CRO ou Chefe de 
Risco. 0 artigo de Kleffner, Lee e McGannon (2003) examina o uso do ERM pelas companhias canadenses, as características que estão associadas com seu uso, os obstáculos na sua implementação e o papel das diretrizes da governança corporativa na decisão da adoção do ERM. Mais escassos ainda são os trabalhos e artigos referentes às suas boas práticas e estruturas de gestão de risco. Uma grande parte do material identificado e levantado para esse projeto de pesquisa foi de entidades ligadas à área de risco, como COSO, RIMS, CAS, RMA, etc., ou de consultorias que realizaram surveys, caso da Deloitte, Corporate Executive Board e EIU, ou da ABNT/ISSO, que emitiu uma norma específica em final de 2009. 0 resultado desse material encontra-se a seguir.

\section{Boas práticas em gestão de risco}

Três trabalhos serviram de referencial teórico como sendo as boas práticas em gestão de risco. Duas pesquisas, uma realizada pela Economist Intelligence Unit - EIU (2007) e outra pela Deloitte (2008), mais o estudo da Aon (2010) com dez diferentes setores de indústria, fornecem uma base de investigação no pensamento corrente em uma das disciplinas que mais cresce e atrai interesse no mundo dos negócios. As boas práticas apontadas nesses materiais são discutidas a seguir:

\section{a) Risco permeando toda a organização}

Uma década atrás, o escopo da gestão de risco teria sido de evitar perdas financeiras. Há um consenso crescente de que seu escopo é de projetar a imagem corporativa correta aos investidores, clientes e demais parceiros, isto é, melhorar reputação e proporcionar vantagem competitiva. 0 estudo da Aon (2010) mostra que, à medida que as empresas tornam-se melhor no ERM, os benefícios na proteção e melhoria do valor ao acionista aumentam substancialmente e o ERM torna-se uma ferramenta competitiva poderosa. Polizelli (2002), Buehler e Pristsch (2003) advogam a ideia de que tomar risco derradeiramente cria valor ao acionista.

Posição similar é compartilhada no estudo da Marsh/RIMS (2009), no qual as empresas enxergam risco como algo para otimizar, criar valor e não apenas para mitigar ou evitar. Há um esforço para comparar risco contra os concorrentes e contra a própria organização. As questões de risco devem estar no bojo das conversas a respeito das decisões negociais e empresariais.

\section{b) Perigos em áreas não tradicionais de risco}

Os gerentes de risco consideram que suas empresas lidam bem com riscos de crédito, de mercado e financeiros. Por outro lado, a confiança em outras áreas, como risco de capital humano, regulatório, tecnologia de informação e reputação, é mais fraca. A exposição da empresa a diferentes categorias de risco é confirmada também na pesquisa da Kaufman, Oh e Sherman (2009), com cinco categorias de risco, sendo duas delas coincidentes com o da pesquisa da EIU, a saber: risco de tecnologia/segurança de informação e riscos legais/regulatórios.

Fornecedores, clientes, pessoal interno da empresa e demais stakeholders devem ser engajados como fontes de informação na identificação de novos e emergentes riscos (AON, 2010).

\section{c) Existência de diversos direcionadores} que fortalecem a gestão de risco

Esforços na gestão de risco estão sendo direcionados pelos fatores internos e externos. Os respondentes da pesquisa da EIU (2007) afirmam que o principal direcionador interno é o maior compromisso da diretoria da empresa para implementar com sucesso os processos e a estrutura de risco. Antecipação de prejuízos e perdas financeiras, tanto nos seus resultados como nos ativos, é outro fator interno (DELOITTE, 2008). Do lado externo, os principais direcionadores são o foco crescente dos reguladores nas práticas corporativas e as demandas dos investidores para maior transparência e responsabilidade nas informações prestadas.

O estudo de Kaufman, Oh e Sherman (2009) também vai nessa direção, tanto no apoio da diretoria quanto na transparência das informações e pressão dos reguladores como oportunidade de melhoria. No entanto, esse mesmo estudo aponta outros direcionadores importantes, como governança corporativa e pressão das agências de rating.

Nas empresas pesquisadas pela Aon, $100 \%$ daquelas no estágio avançado de ERM reportam que 
a diretoria entende e apoia as atividades de gestão de risco.

\section{d) Criação de um responsável pelo risco}

Há um consenso emergente que decisões referentes a apetite ao risco e estratégia de gestão de risco devem estar em nível central da empresa, mas a implementação daquelas políticas deve estar descentralizada, de responsabilidade dos gerentes de negócio. 0 estudo da Corporate Executive Board (2007) mostra que $48 \%$ mantêm uma estrutura central e $42 \%$ descentralizam por tipo de risco. A figura do CRO, ou Chefe de Risco, já é realidade em 38\% das empresas na pesquisa da EIU e $21 \%$ pretendem criar essa função nos próximos três anos. Corporate Executive Board mostra resultado similar com $42 \%$ delas (na figura do diretor, vice-presidente ou chefe de risco).

Azarchs e Samanta (2005) sustentam que a função do gestor de risco deve ser de independência, significando que este não deve se reportar ao pessoal do front office (gestores da linha de frente, responsáveis pelo mercado) e sim ao CRO, e este, por sua vez, ao Chief Executive Officer - CEO, ou Chefe Executivo. Pesquisa da Deloitte (2008) mostra que o CRO se reporta ao Chief Financial Officer - CFO, ou Chefe Financeiro, em 33\% dos casos e ao CEO em 27\%. A visibilidade organizacional para o CRO pode refletir um compromisso da empresa com o ERM, além de ajudar a estabelecer o estágio para um programa bem-sucedido.

\section{e) Cultura e conhecimento do risco}

Um item determinante de sucesso tem sido a necessidade de assegurar que uma cultura para o risco e seu conhecimento permeiem todos os níveis da empresa. Isso significa que ela deve estabelecer claramente seu apetite ao risco, bem como que processos e sistemas estejam presentes para monitorar riscos. Essa mesma posição é defendida por Taylor (2007) quando diz que o gerenciamento de uma cultura de risco em uma empresa é parte do ERM. 0 estudo da Aon (2010) advoga uma cultura de ERM que encoraja engajamento total e responsabilidade em todos os níveis da empresa.

Pesquisa da Deloitte (2008) chama a atenção para o fato de que processos críticos de tomada de decisão relacionados ao crescimento futuro, como planejamento estratégico, alocação de capital, fusões e aquisições e gestão de desempenho, devem incorporar informação de risco nas decisões.

\section{f) Aumento previsível nos investimentos}

Estudo da Marsh/RIMS (2009) aponta que o investimento em gestão de risco em $42 \%$ das firmas que trabalham com ERM (chamadas de strategic companies) será maior em 2009. No estudo da EIU (2007), empresas de todos os tamanhos e áreas planejam aumentar investimento na maioria das áreas da gestão de risco, a saber: melhoria na qualidade dos dados e relatório, fortalecimento dos processos de avaliação de risco, treinamento gerencial, desenvolvimento de uma estrutura ou modelo de risco e estabelecimento de um comitê de risco e suas responsabilidades.

\section{g) Transparência na comunicação do risco}

Engajar stakeholders no processo de gestão de risco inclui uma troca transparente de informações que apoiam as decisões gerenciais e estratégicas. 0 entendimento de como o risco ao longo da cadeia de valor afeta os objetivos de negócio e desempenho é um benefício dessa transparência. No estudo da Aon, 93\% das empresas pesquisadas em estágio avançado engajam stakeholders na troca de informações e $71 \%$ desse grupo relatam sucesso no esforço de permear uma cultura de risco nas suas empresas.

h) Uma última boa prática refere-se à necessidade das empresas de terem ou não uma estrutura formal ou modelo de gestão de risco corporativo

Na pesquisa realizada por Kaufman, Oh e Sherman (2009), 79\% dos respondentes indicam que suas empresas empregam uma estrutura formal de ERM, seja no estágio inicial (28\%) ou estágio maduro (48\%). Contudo, 54\% dos respondentes indicam que sua estrutura de ERM não tem aderência a nenhum modelo ou estrutura externa. Dos $46 \%$ restantes, $67 \%$ deles aderiram ao modelo do COSO e 16,2\% adotaram a estrutura AS/NZS 4360. Ambos os modelos fornecem uma estrutura de melhores práticas na gestão de risco. 
Dois outros estudos mostram resultados mais tímidos. Um da Deloitte (2008), em que 35\% das empresas afirmam terem um padrão específico, contra $37 \%$ que não escolheram ainda. Daquelas que escolheram a estrutura do COSO é a mais popular (80\%), seguida da AS/ NZS 4360 (9\%). 0 estudo da Corporate Executive Board (2007) mostra que apenas $48 \%$ das empresas estabeleceram total ou parcialmente o ERM. No entanto, das empresas pesquisadas, $52 \%$ responderam ter implementado ou planejam implementar o modelo do COSO.

Níveis de evolução de gestão de risco nas empresas

Aon (2010) classifica a evolução de uma estrutura de ERM em cinco estágios de processo de maturidade, conforme ilustrado no Quadro 1.

Marsh/RIMS (2009) classificam os enfoques de gestão de risco em tradicional, progressivo e estratégico (Quadro 2).

O estudo de Beasley, Clune e Fermanson (2005) com 123 organizações norte-americanas e internacionais defende que o estágio de implementação do ERM é positivamente relacionado, determinado através de regressão multivariada, com os seguintes fatores: presença do CRO na gerência sênior da empresa; independência da diretoria na qual $76 \%$ dos seus membros representam diretores independentes; suporte do CEO e do CFO; presença de auditoria independente e tamanho da organização. Com exceção dos dois últimos fatores, os demais fatores estão em linha com as boas práticas descritas na seção anterior.

0 artigo de Abrams et al. (2007) mostra que os negócios evoluem sua resposta ao risco ao longo de uma continuidade, conforme Figura 1.

No estágio de Atender, os negócios visam evitar penalidades, frequentemente implementado por meio de auditoria de manuais e procedimentos dos processos existentes. Enquanto isso possa ajudar a atender a legislação, esse enfoque é reativo e não integrado às operações do dia a dia. À medida que os negócios percebem que esse enfoque deve ser sustentado e adaptado para atender as mudanças da legislação, eles entram no estágio de Melhorar.

Quadro 1 - Cinco estágios de processo de maturidade

\begin{tabular}{ccl}
\hline Escala & Estágio & \multicolumn{1}{c}{ Descrição } \\
\hline 1 & Inicial & $\begin{array}{l}\text { Atividades associadas são muito limitadas no escopo e podem ser implementadas em base } \\
\text { ad-hoc. }\end{array}$ \\
2 & Básico & $\begin{array}{l}\text { Limitadas competências para identificar, avaliar, gerenciar e monitorar riscos. } \\
\text { Suficientes competências para identificar, medir, gerenciar e monitorar riscos; políticas e téc- } \\
\text { nicas são definidas e utilizadas (ocasionalmente de forma independente) por toda a organi- } \\
\text { zação. } \\
\text { Consistente habilidade para identificar, medir, gerenciar, reportar e monitorar riscos; consis- } \\
\text { tente aplicação de políticas e técnicas por toda a organizaça. } \\
\text { Habilidade bem desenvolvida para identificar, medir, gerenciar e monitorar riscos; processo é } \\
\text { dinâmico e capaz de se adaptar aos riscos e ciclos de negócio; explícita consideração do risco e } \\
\text { gestão do risco em decisões gerenciais. }\end{array}$ \\
\hline
\end{tabular}

Fonte: Dados da pesquisa.

Nesse estágio, os negócios visam melhorar eficiência operacional por meio de redução de controles ineficazes ou duplicados e o uso de controles automatizados. Outros negócios poderão tentar integrar risco como parte da estratégia global e, assim, ganhar visibilidade e transparência nas suas operações.

À medida que as empresas entram no estágio de Transformar, elas adotam um enfoque holístico e otimizado da gestão de risco, olhando os eventos e classificando-os em riscos e oportunidades. Nesse estágio, o valor gerado pelo risco integrado ao negócio supera os seus custos.

\section{Modelos ou estruturas de ERM}

Três estruturas são mostradas nesse trabalho: do COSO (Figura 2), do AS/NZS 4360 e a da ABNT NBR ISO 31000. 
Quadro 2 - Classificação dos enfoques de gestão de risco

\begin{tabular}{lll}
\hline \multicolumn{1}{c}{ Enfoque tradicional } & \multicolumn{1}{c}{ Enfoque progressivo } & \multicolumn{1}{c}{ Enfoque estratégico } \\
\hline 1. Identificação do risco, controle de perda & Enfoque tradicional mais: & Enfoques tradicional e progressivo mais: \\
e análise das reclamações. & 1. Continuidade do negócio, custo & 1. ERM por toda a empresa e uso de \\
2. Aumentar habilidade para atender os & total do risco, educação e comuni- & tecnologia. \\
objetivos corporativos assegurando que & cação. & 2. Questões de risco são parte das dis- \\
riscos são levados em consideração nas & 2. Melhorar competências para iden- & cussões estratégicas da empresa. \\
decisões. & tificar e avaliar riscos. & 3. Fontes de risco são obtidos em todos \\
3elhorar gestão dos riscos inter-relacio- & 3. Melhorar gestão e responsabili- & os níveis da empresa e com os stake- \\
nados por toda a organização. & dade das unidades de negócio. & holders. \\
& 4. Auditoria interna leva as questões & \\
& de risco para discussão. & \\
\hline
\end{tabular}

Fonte: Dados da pesquisa.

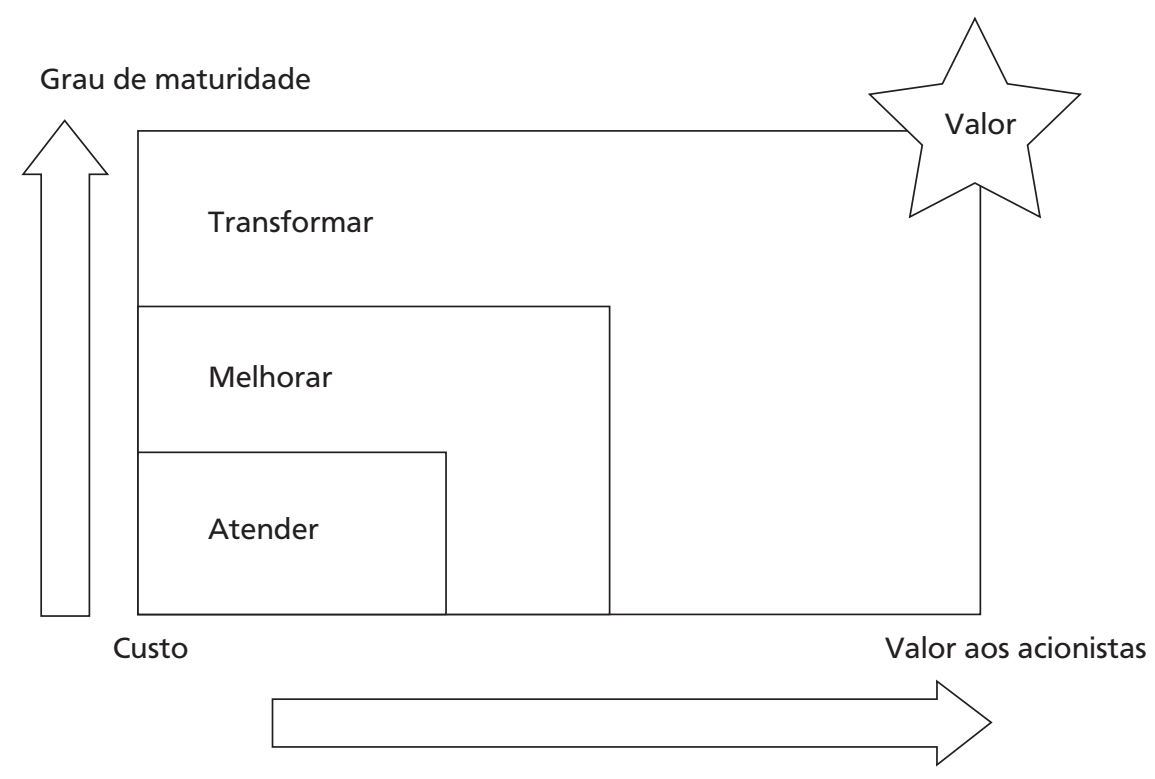

Figura 1 - Continuidade do ERM

Fonte: Dados da pesquisa.

\section{Estrutura do COSO - Committee of Sponsoring Organizations (COSO, 2004).}

A estrutura de gerenciamento de riscos corporativos é direcionada para o alcance dos objetivos, dividida em quatro categorias:

a) estratégicos - objetivos gerais, alinhados e que dão suporte à missão da empresa;

b) operacionais - eficiência e eficácia na utilização dos recursos;

c) divulgação/reporte - confiabilidade nos relatórios divulgados; d) compliance - atendimento às leis e aos regulamentos aplicáveis.

0 gerenciamento de riscos corporativos constitui-se de oito componentes inter-relacionados. Estes são derivados do modo como a gerência conduz a empresa e são integrados com o processo de gerenciamento. Os componentes são:

- ambiente interno - o ambiente interno engloba o tom da organização e estabelece as bases pelas quais o risco é visto e solucionado pelas pessoas da entidade, incluindo filosofia de gerenciamento 
e apetite ao risco, integridade e valores éticos e o ambiente no qual a empresa opera;

- estabelecimento de objetivos - os objetivos devem ser definidos antes da direção poder identificar eventos potenciais de risco que afetem sua realização. 0 gerenciamento de riscos corporativos assegura a existência de um processo para estabelecer objetivos, de forma que os objetivos escolhidos deem suporte e alinhem-se à missão da entidade e sejam consistentes com o seu apetite ao risco;

- identificação de evento - eventos internos e externos que possam afetar a realização dos objetivos da entidade devem ser identificados e separados entre riscos e oportunidades.
A identificação de evento deve levar em conta: o evento, os fatores que influenciam as estratégias e os objetivos, as técnicas e metodologias, os eventos interdependentes, as categorias de eventos e os riscos e oportunidades;

- avaliação de risco - riscos são analisados considerando-se sua probabilidade e impacto, como uma base para determinar como eles deveriam ser gerenciados. São avaliados em uma base inerente e em outra residual. O Risco Inerente é o risco a uma entidade na ausência de todas as ações que a gerência possa tomar para alterar a probabilidade ou o impacto do risco. 0 Risco Residual é o risco que remanesce depois que a gerência responde ao risco;

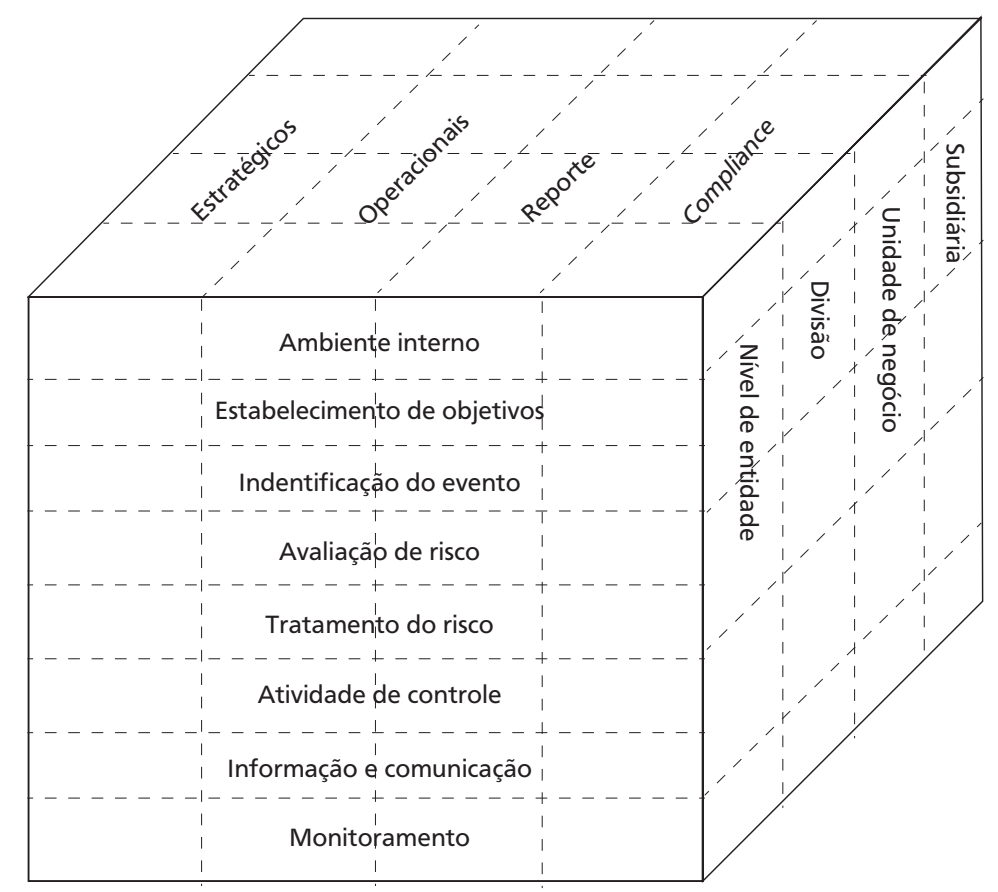

Figura 2 - Modelo do COSO

Fonte: Dados da pesquisa.

- tratamento do risco - a gerência seleciona o tratamento do risco - evitar, aceitar, reduzir ou dividir - desenvolvendo um conjunto de ações para alinhar os riscos com a tolerância e o apetite ao risco da entidade;

- atividades de controle - políticas e procedimentos são implementados para ajudar a assegurar que os tratamentos dos riscos sejam executados. Essas atividades são necessárias para assegurar que as respostas ao risco estejam sendo realizadas corretamente e de uma maneira oportuna;

- informação e comunicação - as informações relevantes são identificadas, capturadas e co- 
municadas em formato e periodicidade que possibilitem às pessoas cumprirem com suas responsabilidades;

- monitoramento - a totalidade do gerenciamento de riscos corporativos é monitorada, e alterações para melhoria são efetuadas sempre que necessário. 0 monitoramento é realizado mediante atividades gerenciais contínuas, avaliações separadas ou por ambas.

Estrutura da Australian/New Zealand

Standard (AS/NZS 4360)

O CAS Enterprise Risk Management Committee (2003) apresenta os sete passos do processo de gestão de risco, que são baseados no modelo AS/NZS 4360 (Figura 3).
- Estabelecer contexto - esse passo inclui contextos externo, interno e gestão de risco: Contexto externo começa com definição da relação da empresa com seu ambiente (inclui análise SWOT) e a identificação dos vários stakeholders.

Contexto interno começa com entendimento dos objetivos gerais da empresa, suas estratégias e os indicadores-chave.

Contexto de gestão de risco estabelece o apetite ao risco e identifica as categorias de risco relevantes para a empresa e o grau de coordenação dentro da empresa.

- Monitorar riscos - esse passo envolve documentar as condições e eventos que representam ameaças materiais para a realização dos objetivos da empresa ou representam áreas para explorar vantagem competitiva.

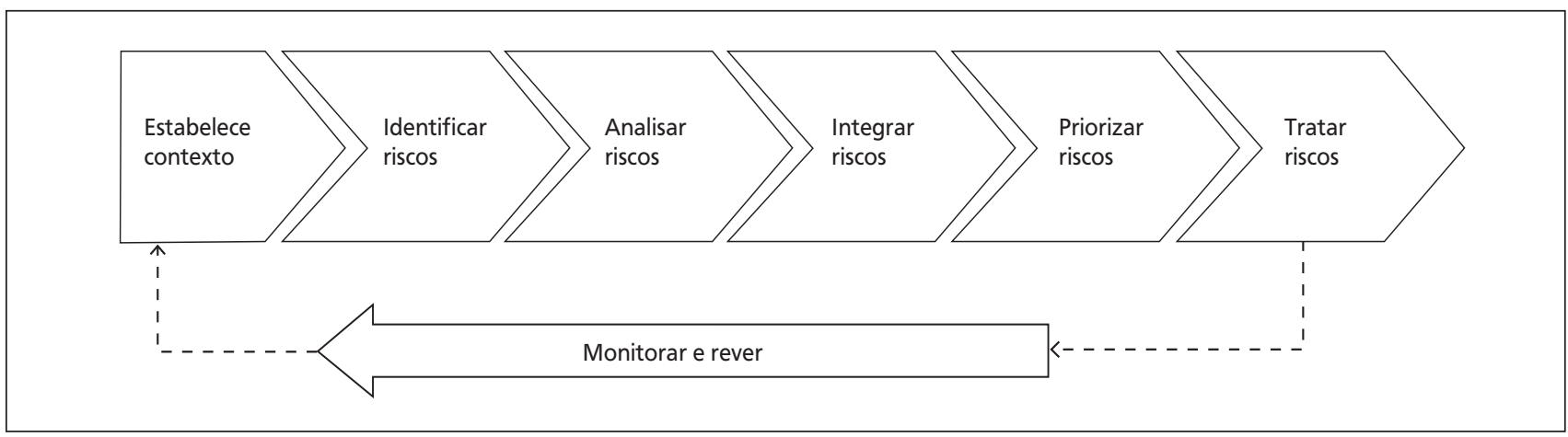

Figura 3 - Modelo da AS/NZS 4360

Fonte: Dados da pesquisa.

Uso de métodos como auditoria interna, pesquisas, workshops internos auxiliam a identificar os riscos significativos.

- Analisar e quantificar riscos - esse passo envolve criar probabilidades de ocorrência para cada tipo de risco material. Técnicas de análise vão de qualitativo a quantitativo, como análise de sensibilidade, análise de cenário e de simulação. Considerar fazer hedge contra desvalorização cambial, fazer uma estimativa de impactos financeiros em uma longa negociação com o sindicato da categoria. Estudos atuariais referentes a plano de previdência privada e seguro médico aos colaboradores ou monitoramento dos preços dos commodities são algumas das situações em que a empresa analisa e quantifica os riscos.
- Integrar riscos - envolve agregar todas as probabilidades de ocorrência dos riscos, fazer correlações entre eles e expressar os resultados em termos do impacto nos indicadores chave da empresa. Construção de um modelo estrutural de simulação para integrar todos os riscos é um exemplo desse passo.

- Priorizar riscos - esse passo envolve determinar a contribuição de cada risco para o perfil de risco agregado da empresa e priorizar adequadamente, de modo que as decisões possam ser tomadas quanto ao correto tratamento. O desenvolvimento de um Mapa de Risco, em que serão cruzados todos os riscos nos seus dois componentes - frequência e impacto de ocorrência -, pode ajudar a priorizar esses riscos. 
- Tratar riscos - esse passo compreende um número de diferentes estratégias, incluindo decisões de como evitar, reter, reduzir, transferir ou explorar risco. Para a categoria de risco hazard, o mecanismo de transferência tem sido o mercado de seguros. Com respeito a riscos financeiros, mercado de capitais tem sido auxílio às empresas em lidar com commodities, taxa de juros e risco cambial. Quanto a riscos estratégicos, empresas não têm tido mecanismos de transferência, mas simplesmente de evitar ou reter esses riscos.

- Monitorar e rever - esse último passo envolve acompanhar periodicamente o ambiente de risco e o desempenho das estratégias de gestão de risco. Os resultados dessas constantes revisões são retroalimentados e o ciclo se repete. Um comitê de gestão de risco que se reúne frequentemente para monitorar o progresso nas metas estabelecidas é um exemplo desse passo.

Estrutura da ISO International Organization for Standardization 31000 (ABNT, 2009)

- A estrutura da ISO 31000 pretende auxiliar a organização a integrar a gestão de riscos em seu sistema de gestão global (Figura 4).

- Mandato e comprometimento - a introdução da gestão de riscos e a garantia de sua contínua eficácia requerem comprometimento forte e sustentado a ser assumido pela administração da organização.

- Concepção da estrutura para gerenciar riscos - a organização deve avaliar e compreender os contextos externo e interno, em seguida estabelecer os objetivos e o seu comprometimento em relação à gestão de riscos, assegurar que haja responsabilização, autoridade e competência apropriadas para gerenciar riscos, integrar em todas as práticas e processos de forma eficaz e eficiente, alocar recursos apropriados e, por fim, estabelecer mecanismos de comunicação internos e externos.

- Implementação da gestão de riscos por meio de uma estrutura que atenda aos requisitos legais e regulatórios e assegure a tomada de decisões alinhada com os resultados dos processos de gestão de riscos.

- Monitoramento e análise crítica da estrutura - a organização deve medir o desempenho da gestão de riscos, utilizando indicadores e reporte sobre os riscos e progressos.

- Melhoria contínua da estrutura - convém que decisões sejam tomadas sobre como a política, o plano e a estrutura da gestão de riscos podem ser melhoradas e que elas visem melhorias na capacidade de gerenciar riscos da organização.

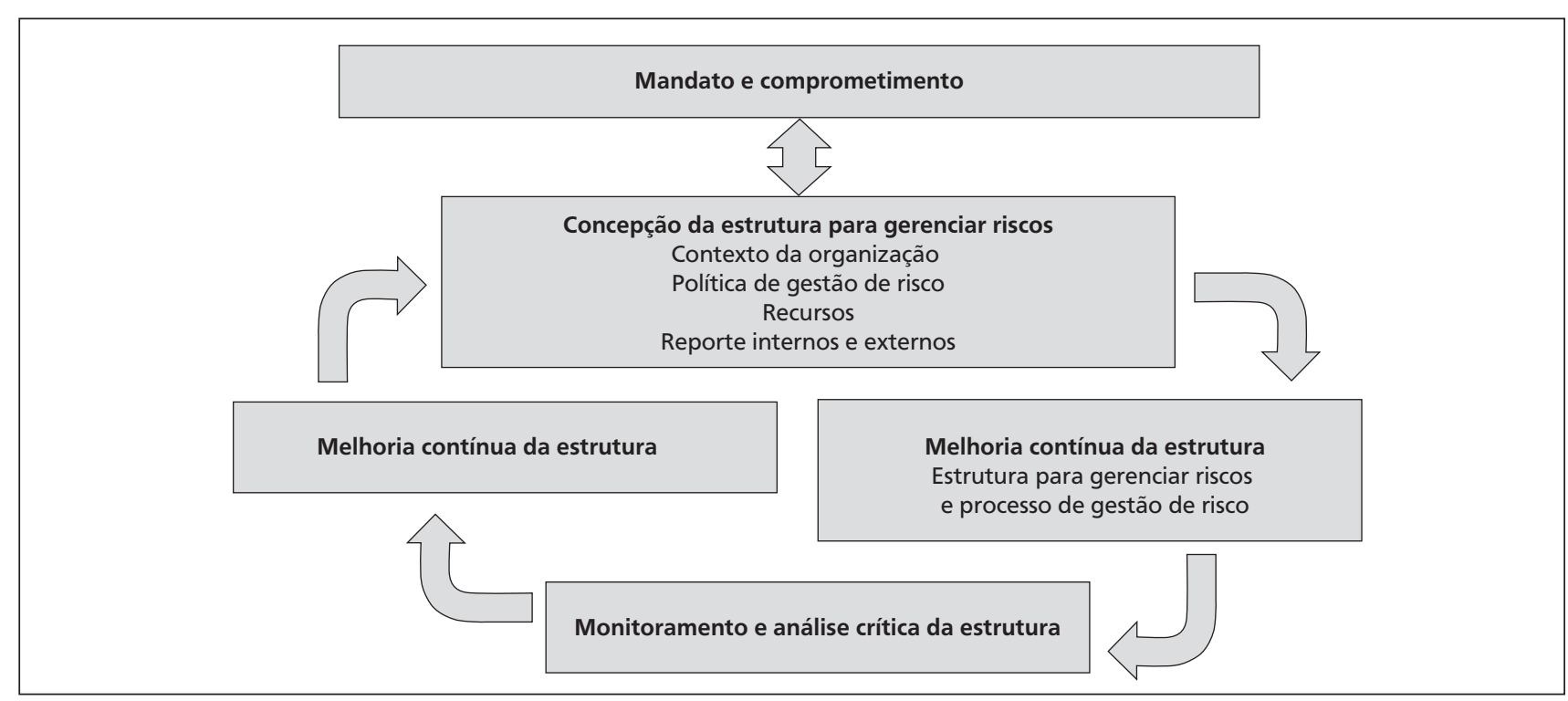

Figura 4 - Estrutura de gestão de riscos da ABNT/ISO 310000

Fonte: Dados da pesquisa. 


\section{Procedimentos metodológicos}

Essa pesquisa é aplicada quanto a sua natureza e com objetivo exploratório. A estratégia de abordagem é o estudo de um único caso. A pesquisa exploratória pode constituir-se numa estratégia capaz de desvendar as particularidades do fenômeno objeto de estudo por meio de sua delimitação (OLIVEIRA, 2007). 0 estudo de caso, por sua vez, é uma estratégia de pesquisa que contribui com o conhecimento que temos dos fenômenos individuais, organizacionais, sociais, etc. Ele conta com muitas das técnicas utilizadas pelas pesquisas históricas, mas acrescenta duas fontes de evidências que usualmente não são incluídas no repertório de um historiador: observação direta dos acontecimentos que estão sendo estudados e entrevistas das pessoas nelas envolvidas (YIN; GRASSI, 2005).

Quanto à coleta de dados, documentos internos foram fornecidos pela empresa, bem como obtidos através de entrevistas semiestruturadas com dois gestores - Superintendente de Auditoria Interna e Consultor Sênior de Controles Internos. Foi feito um corte no tempo, pois tanto os documentos quanto as entrevistas ocorreram entre o último trimestre de 2009 e o primeiro de 2010. Por fim, foi feita uma análise qualitativa dos dados com a finalidade de verificar a aderência das práticas de gestão de risco utilizadas na Congás com as boas práticas do mercado.

O problema de pesquisa é "Qual a eficiência com que as empresas estão gerenciando os riscos à luz das melhores práticas?". Os objetivos da pesquisa são: a) fazer uma comparação das práticas de gestão de risco utilizadas no estudo de caso com as boas práticas do mercado, tendo por base as boas práticas extraídas de três estudos; b) pesquisar diferentes modelos ou estruturas de gestão de risco corporativo e se o seu emprego contribui para a eficiência na gestão desses riscos.

O estudo de caso foi realizado na Companhia de Gás de São Paulo - Comgás, empresa do ramo de distribuição de gás canalizado do estado de São Paulo.

Com o estudo de caso, pretende-se identificar o nível de eficiência em que a empresa está gerenciando seus riscos corporativos à luz das melhores práticas, bem como saber se a estrutura adotada de gestão de riscos contribui para essa eficiência.

\section{Estudo de caso}

O estudo de caso será apresentado em quatro tópicos: o primeiro trata da apresentação da empresa Comgás, o segundo mostra a cadeia de valor dessa empresa, no terceiro tópico é discorrida a sua gestão de risco corporativo e, por fim, os resultados das entrevistas feitas com os gestores.

\section{A Comgás}

A Comgás foi privatizada em maio de 1999 e tem como acionistas a British Gas e a Shell. É hoje a maior distribuidora de gás natural canalizado do país. Conta com mais de cinco mil quilômetros de rede, levando gás natural para mais de 800 mil consumidores no segmento residencial, comercial e industrial. Sua área de concessão abriga cerca de um quarto do Produto Interno Bruto do país, abrangendo 177 municípios das regiões metropolitanas de São Paulo, Campinas, além da Baixada Santista e do Vale do Paraíba.

A meta da administração da Comgás é expandir a companhia e torná-la a maior distribuidora de gás natural da América Latina, tendo como base a qualidade, a segurança e o respeito pelo meio ambiente. A Comgás é dividida em três negócios: residencial, comercial e industrial. A empresa alcançou em 2008 mil clientes industriais. Esse negócio da empresa vem crescendo significativamente e representa a sua maior parcela. Ela conta hoje com mais de 3.000 funcionários diretos e indiretos.

\section{Cadeia de valor da Comgás}

Na sua Cadeia de Valor estão descritos todos os processos de negócio, desde o planejamento do negócio até o pós-venda, e os processos de suporte necessários para o funcionamento dos processos de negócio (Figura 5).

A Comgás entende que processo é o modo de operar, de forma sistêmica e padronizada, todas as atividades da empresa, visando atingir o resultado esperado. Ela conta com a seguinte estrutura para avaliar todos os processos ao longo da cadeia e aplicar controles de mitigação dos riscos:

a) comissão de gerenciamento de riscos - CGR: é realizado mensalmente um encontro entre 
todos os diretores, gerentes e superintendentes relacionados com área de riscos e o presidente com o objetivo de avaliar todos os riscos da companhia e criar ações para os controles desses riscos;

b) comitê de diretoria: tem por objetivo avaliar e aprovar todas as ações mitigatórias para controlar os riscos que foram apresentados pela CGR;

c) atividades de compliance: os superintendentes e gerentes de todas as áreas da companhia possuem a responsabilidade de monitorar os riscos continuamente através dos controles apresentados, pela conscientização de todos os funcionários e colaboradores quanto a estes riscos e comunicar fatos verídicos em forma de "Lições Aprendidas" para que não possam afetar negativamente os resultados;

d) comitê de auditoria: a principal função da $\mathrm{Au}$ ditoria Interna dentro da Comgás é verificar a efetividade dos controles internos.

\section{Gestão de risco corporativo na empresa}

Em 2004, devido a exigências da Lei SarbannesOxley, os departamentos de Controles Internos e Auditoria Interna foram separados e começaram a trabalhar individualmente. A área de Controles Internos ficou responsável por fazer o gerenciamento dos riscos encontrados e atualizá-los conforme a mudança do cenário interno e externo. A área de Auditoria Interna ficou responsável pela avaliação do gerenciamento, ou seja, verificar se todos os controles estabelecidos estão sendo gerenciados de maneira eficaz.

Em 2005, a empresa adotou uma estrutura de gestão de risco baseada totalmente no modelo do COSO. Para aperfeiçoar e agilizar a identificação, registro, análise, unificação e integração dos riscos, a Comgás implantou o software SGIR - Software de Gestão Integrada de Riscos.

Em 2006, foi criada a CGR vinculada ao Comitê de Diretores. Quando um risco é identificado, uma

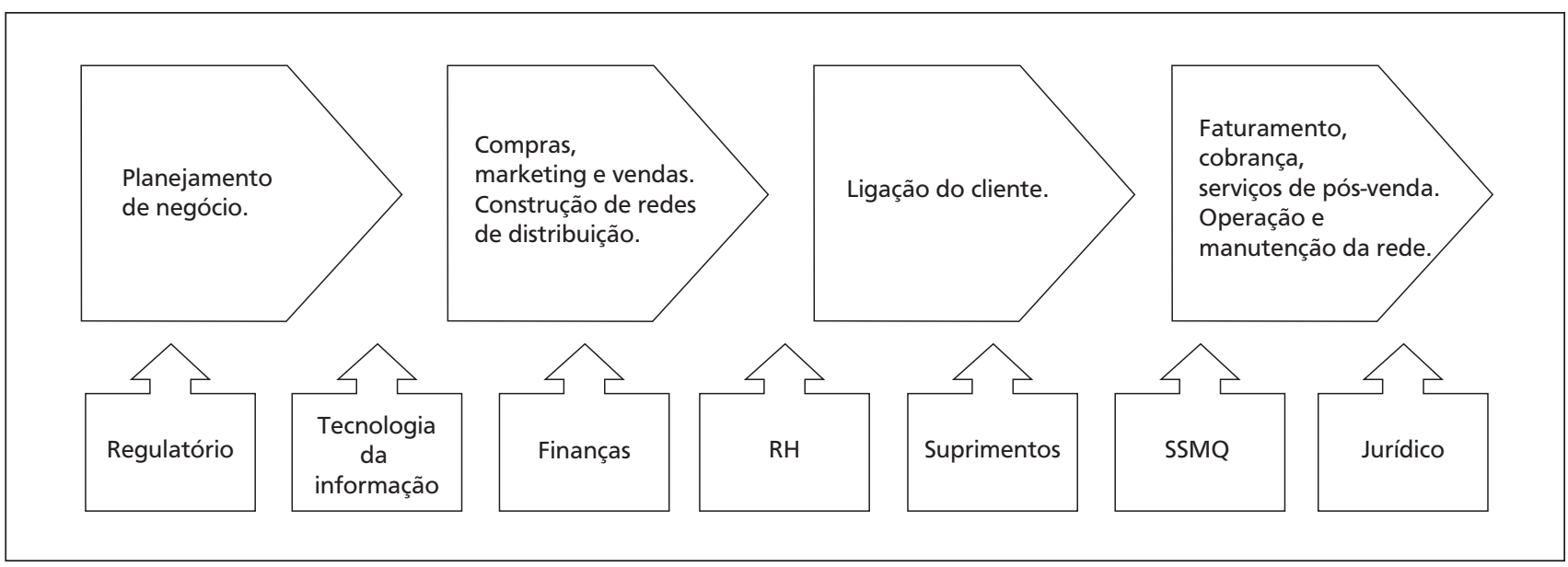

Figura 5 - Cadeia de valor da Comgás (Intranet Comgás - outubro 2008)

Fonte: Dados da pesquisa.

primeira avaliação da CGR determina se ele é ou não relevante para o negócio, bem como sua categoria. Se relevante, ele é incluído na Matriz de riscos da Companhia e avaliado (Figura 6). Na avaliação do impacto, o gestor deve identificar de que forma esse risco afeta o negócio e quanto isso representa em valor, consideradas todas as variáveis (financeira, imagem, reputação, etc.), que em última análise vão representar uma potencial perda financeira. Já a avaliação da probabilidade de ocorrência do risco leva em conta o cenário interno e externo, político, econômico, social.

Para se fazer uma análise da matriz acima é necessário entender a existência do risco residual e inerente. 0 risco inerente é o risco bruto calculado pela multiplicação do impacto (\$) com a probabilidade (\%), ou seja, é o risco que até o momento não foi tratado pela empresa. A partir do momento que a empresa cria planos de ações para mitigar esse risco, este passa a ser considerado residual, onde é feito o 


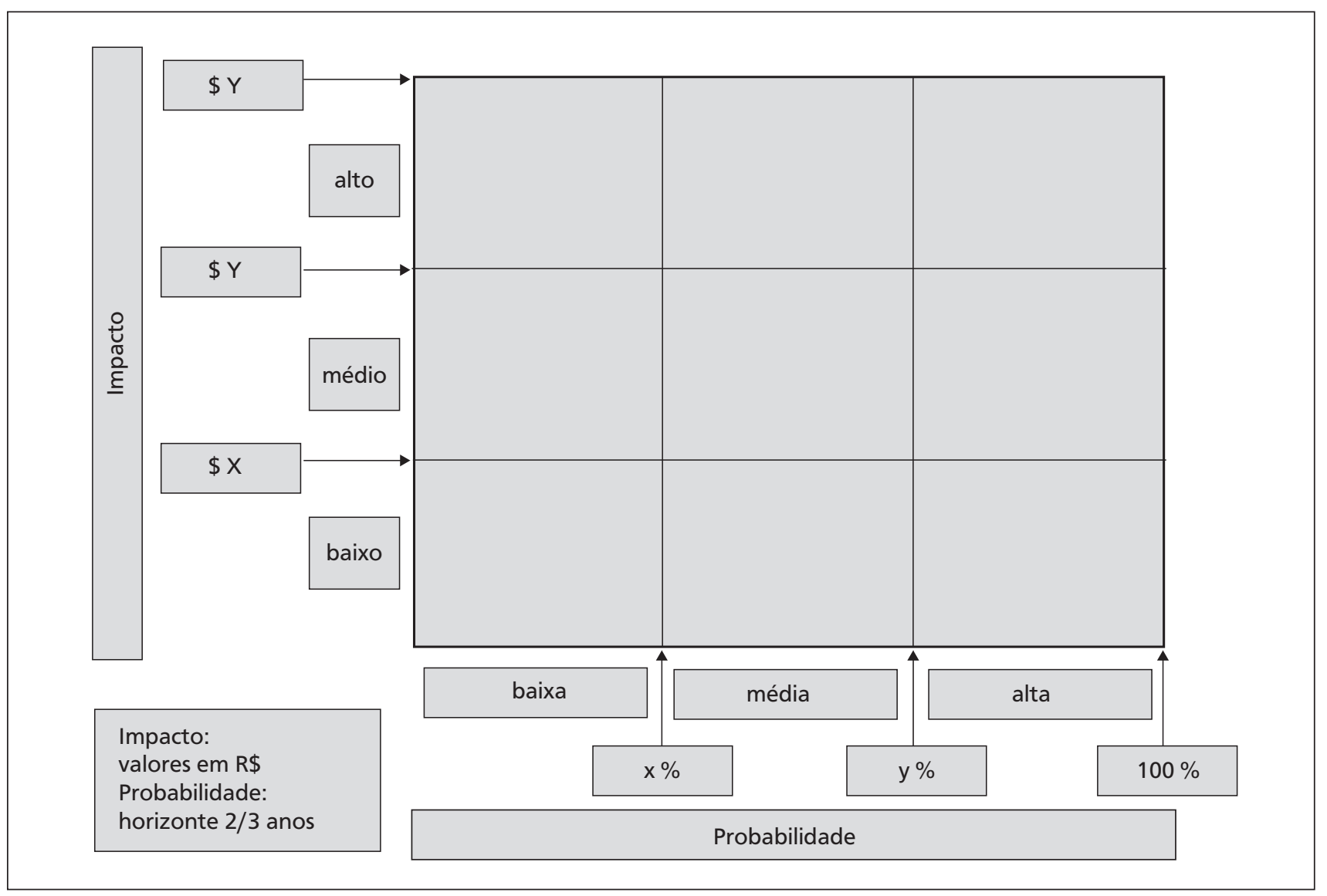

Figura 6 - Matriz de Risco - (Risk Management da Comgás, 2008)

Fonte: Dados da pesquisa.

cálculo novamente para verificar se a ação tomada foi eficaz.

O critério de avaliação de risco fundamenta-se na graduação em maior ou menor grau das variáveis impacto e probabilidade de ocorrência, sendo cada uma das variáveis classificadas como alta, média ou baixa, dentro de uma escala de valores predeterminada, variando de 0 a $100 \%$.

Mensalmente, os membros da CGR se reúnem para apresentar os riscos e suas categorias de maior relevância de cada diretoria, que são os riscos residuais enquadrados na parte superior dianteira da matriz de riscos, e suas devidas ações mitigatórias. Sob a coordenação de Controles Internos, cada gestor, com o auxílio de sua equipe, é responsável por prospectar, avaliar, mensurar e propor as medidas de mitigação, sejam controles já existentes ou planos de ação, nesse caso deve haver um responsável e prazo definido para implementação.

De acordo com a periodicidade e critérios de revisão, as principais alterações sobre riscos são avaliadas mensalmente pela CGR e posteriormente aprovadas em Reunião de Diretoria.

Tipos de atividades de controle

a) políticas e procedimentos: controle preventivo de forma a definir, de maneira formal, as regras internas e necessárias ao funcionamento de todas as áreas da empresa;

b) níveis de aprovação: outro controle preventivo que implica na verificação com o propósito de saber se a atividade foi concluída e validada, em conformidade com as políticas e os procedimentos;

c) conciliação: controle detectivo que permite conciliar as informações abordadas de diferentes bases, adotando ações corretivas, quando necessárias;

d) avaliação de trabalho: acompanhamento detectivo dos processos e serve como avaliação 
dos colaboradores quanto à sua adequação e desempenho em relação às metas e objetivos, de forma a antecipar mudanças que impactam negativamente nos resultados esperados;

e) segurança da informação: reconhece a proteção da confidencialidade, da integridade e da disponibilidade das suas informações contra vários tipos de ameaças;

f) avaliação de controles internos: é o gerenciamento da análise dos riscos associados ao não cumprimento das metas e objetivos operacionais, de informação e de conformidade.

Cabe à Auditoria Interna fazer uma avaliação própria dos riscos, confrontando-a com a avaliação feita pelos agentes de compliance, levando em consideração a probabilidade de sua ocorrência, impacto nas operações e quais ações corretivas devem ser necessários para administrá-los. A auditoria utiliza-se dos seguintes mecanismos:

- identificação dos riscos: mapeamento dos riscos inerentes, nos níveis estratégicos e operacionais, através da identificação da exposição da companhia aos fatores de riscos internos e externos;

- análise de riscos: estimativa dos impactos dos riscos e probabilidade de sua ocorrência na companhia, além de avaliações quanto à forma de gerenciamento dos riscos, ações necessárias para sua redução e respectivo custo dessas ações. A análise dos riscos deve contemplar a avaliação dos riscos residuais e inerentes às atividades;

- gestão de mudanças: alterações na estrutura interna, no cenário econômico ou em outros elementos externos devem ser continuamente monitoradas para que seus impactos sejam identificados e endereçados dentro da análise de riscos da companhia.

\section{Resultados das entrevistas com os gestores}

As entrevistas consistiram de um questionário com perguntas abertas sobre as boas práticas de gestão de risco e tiveram a finalidade de obter a percepção deles quanto à aplicação dessas práticas na Comgás. Os resultados sumarizados seguem.
Quanto ao ambiente interno: inúmeras dificuldades durante a implantação, sendo as principais a falta de uma cultura da empresa voltada ao risco e o desconforto dos colaboradores; no entanto, a percepção do risco e seu apetite ainda não se enraizaram nos níveis mais baixos da empresa; Categorias de risco: a empresa lida bem com todas as categorias, exceto os riscos estratégicos, talvez por serem mais intangíveis; os demais riscos são analisados considerando sua probabilidade e impacto, como base para determinar como estes deveriam ser gerenciados para alcançar os objetivos corporativos; Comunicação: as informações relevantes, notadamente sobre os riscos e seu tratamento, são comunicadas a todos os colaboradores, usando a intranet; Modelo de gestão de risco: este é percebido muito mais como ferramenta para mitigação de risco e, em menor escala, como ferramenta para enxergar novas oportunidades de negócio; Direcionadores: o compromisso da diretoria bem como demanda dos investidores para maior transparência (por conta dos sócios estrangeiros) tem fortalecido a gestão de risco.

\section{Análise dos dados}

Conforme dito anteriormente, os dados da empresa foram obtidos nos documentos internos fornecidos, nas entrevistas com dois gestores e visita in loco. Essa análise tem uma abrangência limitada, visto que se baseia na opinião de dois entrevistados que trabalham na própria empresa. Um número maior de entrevistados e de diversos setores da empresa contribuiria para aumentar sua abrangência. A primeira parte da análise será comparar as práticas utilizadas na Comgás com as melhores práticas do mercado, a saber:

Risco permeando toda a organização: não há evidências claras na documentação recebida de que o escopo da gestão de risco na Comgás não seja outro que o de evitar perdas financeiras; o ERM não é visto como uma ferramenta competitiva para realçar o valor do acionista. Isso foi confirmado na percepção dos gestores.

Atenção em áreas não tradicionais de risco: na opinião dos gestores, a empresa não endereça adequadamente os riscos estratégicos. Adicionalmente, a documentação mostra que os riscos não tradicionais, como de capital humano, de segurança de informação e reputação não são tratados no seu ERM. Não 
há engajamento, sobretudo, dos stakeholders como fontes de informação de novos e emergentes riscos.

Direcionadores internos e externos fortalecendo a gestão de risco: a diretoria e gerência sênior da empresa apoiam e estão comprometidos com a gestão de risco. Isso é evidenciado pelas ações do CGR, Comitê de diretoria e pelas ações das áreas de Controles Internos e Auditoria Interna. Pressão das agências de rating e de órgãos reguladores não é vista como oportunidade de melhoria.

Responsabilidade pelo risco na empresa: não existe a figura de um CRO desvinculada de outras atribuições funcionais. A responsabilidade pela gestão de risco é personificada na figura do diretor financeiro que é o chairman da CGR. Tampouco existe a descentralização das políticas de risco aos gerentes de negócio.

Cultura e conhecimento do risco: na opinião dos gestores, a percepção do risco e seu apetite não se enraizaram por completo; é um ponto em que a Comgás está trabalhando firmemente.

Aumento nos investimentos: os gestores não puderam fornecer valores ou percentual a ser investido, porém afirmaram que investimentos estão sendo feitos no treinamento sobre ferramentas financeiras e na segurança de informações.

Transparência na comunicação: as informações relevantes sobre os riscos e seu tratamento são comunicadas a todos os colaboradores usando a intranet. Ela entende como o risco ao longo da sua cadeia de valor pode afetar os seus objetivos e é transparente na maneira como avalia os processos ao longo da cadeia.

Estrutura formal ou modelo de gestão de risco corporativo em uso: a Comgás tem um modelo baseado totalmente no COSO e utiliza ainda um software (SGIR) que agiliza a identificação, registro, análise, unificação e integração dos riscos.

Os resultados citados mostram que a empresa atende três práticas de forma integral (estrutura formal de gestão de risco, transparência na comunicação e aumento nos investimentos), duas de forma parcial (direcionadores externos e cultura e conhecimento do risco) e três não são atendidas (risco permeando a organização, atenção em áreas não tradicionais e a figura do CRO). Pode-se classificar a estrutura de gestão de risco da Comgás entre o estágio definido e o operacional, de acordo com a nomenclatura da Aon (2010), e de enfoque tradicional para progressivo no enfoque da Marsh/RIMS (2009).
A segunda análise é averiguar se o emprego de modelo ou estrutura de gestão de risco corporativo contribui para a eficiência na gestão desses riscos. Estudo da Aon (2010) mostra que 55\% dos respondentes são do nível definido ou operacional e que eles têm uma estrutura formal para identificar, medir, monitorar e gerenciar os componentes de risco. 0 número de respondentes que migraram para o nível avançado (advanced) representa 7\% e relatam que têm uma estrutura dinâmica de ERM que permite adaptação para lidar com as oportunidades e riscos. Outros trabalhos semelhantes, como os do Kaufman, Oh e Shermana (2009) e da Corporate Executive Board (2007) mostram uma grande parcela de empresas empregando uma estrutura formal de ERM, movimento que tem crescido nos anos recentes.

Em nenhum desses estudos e pesquisas foi comprovada estatisticamente uma relação direta entre as empresas que adotaram uma estrutura de ERM e sua eficiência na gestão de risco. Nem foi tampouco o propósito desses estudos. As evidências mostram ser uma condição imprescindível a empresa empregar um modelo ou estrutura de ERM para ser eficiente na sua gestão de risco. A Comgás, seguramente, não teria alcançado o seu nível de eficiência se não tivesse em uso uma estrutura de gestão de risco corporativo. Parece difícil uma empresa não ter uma estrutura formal de ERM e ser, assim, eficiente na gestão de risco fazendo uso das boas práticas de mercado.

\section{Conclusão}

Por tratar-se de um único caso, os resultados apresentados são limitados em termos de significância, representatividade e generalidade. Apesar dessa limitação, a partir dos resultados do estudo de caso da Comgás é possível extrair as seguintes conclusões:

a) o nível de eficiência na gestão de riscos da Comgás tem relação com a utilização das melhores práticas de mercado. Quanto mais práticas estiverem sendo aplicadas na empresa, maior será seu nível de eficiência;

b) o emprego de uma estrutura formal ou modelo de ERM contribui significativamente para essa eficiência.

Essas conclusões respondem ao problema de pesquisa formulado anteriormente e atendem de forma 
positiva os objetivos propostos. No entanto, algumas sugestões seguem abaixo para a Comgás melhorar ainda mais a eficiência da sua gestão de risco:

a) alinhar as avaliações de risco com os objetivos funcionais e de unidades de negócio para promover o pensamento sobre risco nas perspectivas operacional e estratégica. Isso irá encorajar todos os níveis da empresa a focar nos riscos que os colaboradores podem influenciar e controlar;

b) encorajar os colaboradores a pensarem no risco em termos de vantagem competitiva. Quanto melhor eles entenderem os riscos envolvidos, melhor eles podem alavancar oportunidades;

c) o reconhecimento da importância do papel estratégico de um CRO na empresa;

d) assegurar que a diretoria e seus gestores discutam, com alguma frequência, os novos e emergentes riscos no contexto do plano estratégico, plano operacional e seu ambiente externo.

É encorajador observar que mais empresas sejam capazes de direcionar valor através de ERM em áreas como aumento da eficiência operacional, incremento do valor do acionista, otimização do custo total do risco, melhoria da transparência e governança. 0 derradeiro objetivo é ter ERM enraizado na cultura das organizações, nos seus processos gerenciais e visão estratégica, de modo que elas estejam bem posicionadas para capitalizar as oportunidades emergentes.

Uma sugestão de continuidade desse trabalho seria comparar as práticas utilizadas pelas empresas listadas na BMF\&Bovespa com as melhores práticas do mercado, aplicando um questionário dirigido, e comprovar estatisticamente se existe uma relação direta entre as empresas que adotaram uma estrutura de ERM e sua eficiência na gestão de risco.

\section{Referências}

ASSOCIAÇÃO BRASILEIRA DE NORMAS TÉCNICAS - ABNT. NBR ISO 31000: gestão de riscos: princípios e diretrizes. Rio de Janeiro, 2009.

ABRAMS, C. et al. Optimized enterprise risk management. IBM Systems Journal, v. 46, n. 2, p. 219-234, 2007.

AON Global Risk Consulting. Global enterprise risk management survey. Chicago, 2010.
AZARCHS, T.; SAMANTA, P. Independence, control, respect and communication: best practices in ERM. The Risk Management Association RMA Journal, v. 88, n. 1, p. 3640, 2005.

BEASLEY, M. S.; CLUNE, R.; FERMANSON, D. R. Enterprise risk management: an empirical analysis of factors associated with the extent of implementation. Journal of Accounting and Public Policy, n. 24, n. 6, p. 521-533, 2005.

BUEHLER, K. S.; PRISTSCH, G. Running with risk. The McKinsey Quarterly, n. 4, 2003.

CASUALTY ACTUARIAL SOCIETY - CAS. Overview of enterprise risk management, may, 2003.

COMGÁS. Risk management. Annual report. 2008.

COMMITTEE OF SPONSORING ORGANIZATIONS OF THE TREADWAY COMMISSION - COSO. Enterprise risk management - Integrated framework. Executive Summary, September, 2004.

CORPORATE EXECUTIVE BOARD. Are you ready for S\&P's ERM assessment? Washington, 2007.

DELOITTE DEVELOPMENT. Perspectives on ERM and the risk intelligent enterprise. 2008. Disponível em: <www. derloitte.com>. Acesso em: 2 fev. 2011.

ECONOMIST INTELLIGENCE UNIT - EIU. Best practice in risk management. London, UK, 2007.

GÉNÉREUX, C.; LAMARRE, E.; LEAUTIER, T. O. The special challenge of measuring industrial company risk. McKinsey on Finance, n. 6, p. 1-5, 2003.

IBM INSTITUTE FOR BUSINESS VALUE. Risk regulation and return: delivering value through ERM. April, 2005.

KAUFMAN, C.; OH, J.; SHERMAN, H. The importance of ERM during economic upheaval. February, 2009.

KLEFFNER, A. E.; LEE, R. B.; McGANNON, B. The effect of corporate governance on the use of enterprise risk management: evidence from Canada. Risk Management and Insurance Review, v. 6, n. 1, p. 53-73, 2003.

LIENBENBERG, A. P.; HOYT, R. E. The determinants of enterprise risk management: evidence from the appointment of chief risk officers. Risk Management and Insurance Review, v. 6, n. 1, p. 37-52, 2003.

MARSH AND THE RISK AND INSURANCE MANAGEMENT SOCIETY, INC. Excellence in Risk Management VI. Strategic risk management in practice. 2009. 
OLIVEIRA, M. M. De. Como fazer pesquisa qualitativa. Petrópolis: Vozes, 2007.

POLIZELI, J. A. A. A adoção da gestão de risco como fator que agrega valor aos acionistas de empresas não financeiras. 2002. 132 f. Dissertação (Mestrado em Administração) - Universidade Mackenzie, São Paulo, 2002.

TAYLOR, C. Risk culture as part of ERM. The Risk Management Association RMA Journal, v. 89, n. 5, p. 1213, 2007.

VILA, R. Á. Aplicação da gestão do conhecimento em processos de gerenciamento de risco. RAFI, n. 1, 2003.
YIN, R. K.; GRASSI, D. Estudo de caso: planejamento e métodos. Porto Alegre: Bookman, 2005.

Recebido: 26/09/2011

Received: 09/26/2011

Aprovado: 18/10/2011

Approved: 10/18/2011 